This document is a POSTPRINT of the following paper:

\title{
Modeling of Electrokinetic Remediation Combining Local Chemical Equilibrium and Chemical Reaction Kinetics
}

\author{
Matteo Masi a , Juan Manuel Paz-Garcia ${ }^{\mathrm{b}}$, Cesar Gomez-Lahoz ${ }^{\mathrm{b}}$, Maria \\ Villen-Guzman ${ }^{\mathrm{b}}$, Alessio Ceccarini ${ }^{\mathrm{c}}$, Renato Iannelli ${ }^{\mathrm{a}}$

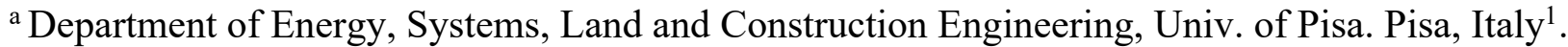 \\ ${ }^{b}$ Department of Chemical Engineering, Faculty of Sciences, Univ. of Malaga. Malaga, Spain. \\ ${ }^{c}$ Department of Chemistry and Industrial Chemistry, Univ. of Pisa. Pisa, Italy.
}

Published

\section{Journal of Hazardous Materials \\ Volume 371, 5 June 2019, Pages 728-733}

https://doi.org/10.1016/j.jhazmat.2019.03.014

For non-commercial repository use only

${ }^{1}$ Corresponding author: Juan Manuel Paz-Garcia, email: juanma.paz@uma.es. 


\title{
Modeling of Electrokinetic Remediation Combining Local Chemical Equilibrium and Chemical Reaction Kinetics
}

\author{
Matteo Masi a , Juan Manuel Paz-Garcia ${ }^{\mathrm{b}}$, Cesar Gomez-Lahoz ${ }^{\mathrm{b}}$, Maria \\ Villen-Guzman $^{\mathrm{b}}$, Alessio Ceccarini ${ }^{\mathrm{c}}$, Renato Iannelli ${ }^{\mathrm{a}}$ \\ ${ }^{a}$ Department of Energy, Systems, Land and Construction Engineering, Univ. of Pisa. Pisa, Italy ${ }^{2}$. \\ ${ }^{b}$ Department of Chemical Engineering, Faculty of Sciences, Univ. of Malaga. Malaga, Spain. \\ ${ }^{c}$ Department of Chemistry and Industrial Chemistry, Univ. of Pisa. Pisa, Italy.
}

\begin{abstract}
A mathematical model for reactive-transport processes in porous media is presented. The modeled system includes diffusion, electromigration and electroosmosis as the most relevant transport mechanism and water electrolysis at the electrodes, aqueous species complexation, precipitation and dissolution as the chemical reactions taken place during the treatment time. The model is based on the local chemical equilibrium for most of the reversible chemical reactions occurring in the process. As a novel enhancement of previous models, the local chemical equilibrium reactive-transport model is combined with the solution of the transient equations for the kinetics of those chemical reactions that have representative rates in the same order than the transport mechanisms.

The model is validated by comparison of simulation and experimental results for an acidenhanced electrokinetic treatment of a real $\mathrm{Pb}$-contaminated calcareous soil. The kinetics of the main $\mathrm{pH}$ buffering process, the calcite dissolution, was defined by a simplified empirical kinetic law. Results show that the evaluation of kinetic rate entails a significant improvement of the model prediction capability.
\end{abstract}

Keywords: Reactive-transport model, calcite dissolution kinetics, electrokinetic remediation, local chemical equilibrium.

${ }^{2}$ Corresponding author: Juan Manuel Paz-Garcia, email: juanma.paz@uma.es. 


\section{Introduction}

Most of the physicochemical processes occurring during Electrokinetic Remediation (EKR) (i.e., the application of electric field for the mobilization of contaminants from soil, sludge, sediment and other porous matrices) are characterized by dynamic behavior. Understanding the influence of the kinetics of these processes can significantly help to elucidate the remediation and to enhance the prediction capabilities of EKR models.

The majority of EKR numerical models have been developed assuming the attainment of chemical equilibrium at each time step of the numerical integration. Models for reactive transport in porous media based on chemical equilibrium assume that the rates of reversible chemical reactions are faster (in both the forward and the backward directions) than the rates of the transport phenomena involved in the process, namely: diffusion, electromigration and electroosmosis [1]. This approach is frequently denoted as the assumption of local chemical equilibrium (LCE) [2], and it has been demonstrated as a suitable approach in many cases [3-10]. However, simulation results often displayed some disagreement with the experimental data in terms of concentration profiles with excessively sharp gradients compared to those obtained experimentally [7,11-13].

The prediction capability of reactive-transport models could be enhanced by taking into account the kinetics of the chemical reactions [14]. Nevertheless, in multi-species and multi-phase systems, the kinetic laws are very case-specific and, therefore, it not straightforward to compile the thermodynamic data necessary for modeling such a kinetic system. Furthermore, the numerical solution of a system described entirely by such laws would be unreliable. Most software for numerical integration presents difficulties at solving stiff partial and differential systems of equations which terms are different in several orders of magnitude [15].

The prediction capability of LCE transport models can be enhanced by taking into account only the kinetics of the "slow" reactions, namely the heterogeneous reactions (i.e., reactions involving different phases), which are generally known to be slower than aqueous-phase equilibrium reactions [16]. As illustrated in Table 1, which shows the characteristic time scales for the main processes of interest in EKR, heterogeneous reactions such as surface complexation and mineral dissolution/precipitation have kinetic rates in the same order than the characteristic rates of the transport phenomena in porous media [15].

In most cases, the contaminant within the treated solid matrix is retained in the solid phase, either as a mineralized compound or as adsorbed species [17]. Therefore, the rate at which target contaminants are released from their mineral-bound forms is essential in EKR treatments. For example, in acid-enhanced EKR treatments, the acid environment generated at the anode dissolves the contaminant-containing minerals into mobile compounds. The progress of the acid front is generally hindered by the presence of buffering minerals such as, for example, calcite. Experimental results have suggested that the dissolution of these carbonates does not take place under equilibrium conditions [18]. 
Table 1. Characteristic Time scales for the main transport and chemical processes of interest in EKR [15].

\begin{tabular}{lllc}
\hline \multicolumn{1}{c}{ Transport Processes } & \multicolumn{2}{c}{ Chemical Processes } \\
\hline Electromigration & $10^{-2}$ & Proton transfer to $\mathrm{H}_{2} \mathrm{O}$ & $10^{-12} \mathrm{~s}$ \\
Electroosmosis & $\mathrm{s}$ & & \\
& $10^{-4}$ & Dissociation of strong acid & $10^{-8} \mathrm{~s}$ \\
Diffusion & $\mathrm{s}$ & & \\
& $10^{-5}$ & Dissociation of weak acid & $10^{-6} \mathrm{~s}$ \\
& $\mathrm{~s}$ & & $10^{-6} \mathrm{~s}$ \\
& & Inorganic complexation & $10^{-2}-10^{4} \mathrm{~s}$ \\
& & Adsorption/Ion exchange & $10^{2}-10^{7} \mathrm{~s}$ \\
\hline
\end{tabular}

In this work, to further develop the prediction capability of EKR models and to understand the role of dissolution kinetics on the rate of extraction of contaminants, the kinetic rates of the calcite dissolution have been taken into account within a reactive-transport model for EKR that combines both the local chemical equilibrium and the kinetic rates. Results presented here show that the proposed model is able to predict EKR processes within porous matrices where the removal of contaminants is limited by the rate of release from the mineral phases.

\section{Materials and methods}

\subsection{Modeled system}

A model was developed and used to simulate the experimental data obtained by Villen-Guzman et al., 2015 [19]. In that work, an EKR treatment was performed on a soil contaminated with a significant amount of $\mathrm{Pb}$. The treatment was enhanced by the addition of acetic acid at the cathode compartment using an automatic $\mathrm{pH}$-control device, assuring a $\mathrm{pH} \leq 5$. The soil used in the experimental work had high content of carbonates, which are known to limit the efficiency of the EKR treatments because they interfere with the entering acidic front. The detailed description of the soil properties were presented in a previous work [20]. The scheme for the acid-enhanced EKR treatment is illustrated in Fig. 1. 


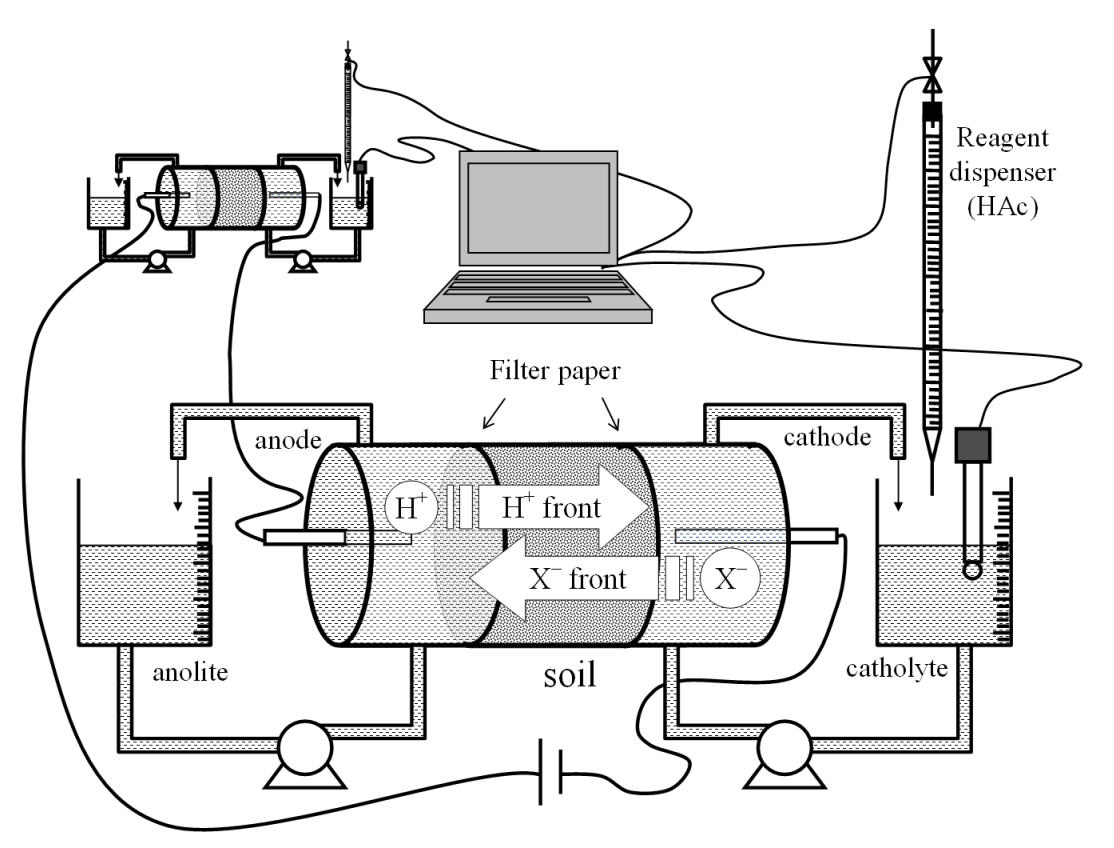

Figure 1. Scheme for an acid-enhanced EKR treatment in horizontal column

The setup used in the experimental work consisted of two horizontal columns $(20 \mathrm{~cm}$ length and $8 \mathrm{~cm}$ inner diameter) electrically connected in series to carry out duplicated experiments. The electrode compartments, placed at each end of the column, were both well stirred and contained $0.5 \mathrm{~L}$ of $1 \mathrm{mM}$ sodium acetate solutions as electrolyte. These compartments were filled with 15 $\mathrm{mm}$ diameter glass spheres with the aim of improving the mechanical stability of the setup. The anode was a mixed metal oxide coated electrode, to promote the electrochemical electrolysis reaction over the oxidation of the electrode material itself. As cathode, stainless steel disc was used. Deposition of metal was not detected at the cathode surface. A constant current density of 2 $\mathrm{mA} \mathrm{cm}{ }^{-2}$ was applied to the soil during $15 \mathrm{~d}$. Metal analysis and $\mathrm{pH}$ measures of daily samples of catholyte and anolyte were carried out during the assays. At the end of the experiments, the columns were disassembled to determine the water content, $\mathrm{pH}$ value, total metal concentration of each of the ten slices of the column soil.

Paz-Garcia et al, in [12] modeled the mentioned experimental data using the assumption of local chemical equilibrium. The chemical system considered in that simulation was the one shown in Table 2. The horizontal column is filled with soil saturated with $0.1 \mathrm{M}$ NaAc solution. The solid matrix was assumed to be formed as combination of a chemically inert part consisting mainly of silicate and aluminosilicate minerals, such as quartz and feldspar; and another part consisting of carbonates, such as calcite and magnetite, that is soluble in acid media. Long term exposure to $\mathrm{Pb}$ contamination produced a carbonated mineral in the form of cerussite and hydrocerussite, observed experimentally via X-ray diffraction with Rietveld refinement [20,21]. For the simulations, the soil was assumed composed by $1.2 \mathrm{~kg}$ of inert material $\left(\rho=2648 \mathrm{~g} \mathrm{~cm}^{-3}\right), 1.2 \mathrm{~mol}$ of calcite and $0.1 \mathrm{~mol}$ of hydrocerussite leading to a soil mixture of $1398 \mathrm{~g}$, with $\rho=2.75 \mathrm{~g} \mathrm{~cm}^{-3}$ and solid volume fraction of $51 \%$ (initial porosity $49 \%$ ). The initial $\mathrm{Ca}$ and $\mathrm{Pb}$ content is, respectively, $34.3 \mathrm{mg} \mathrm{g}^{-}$ ${ }^{1}$ and $44.7 \mathrm{mg} \mathrm{g}^{-1}$ referred to mass of dry solid. 
The model can be used to simulate soils with different edaphological and biological properties. However, including several minerals would increase the number of species in the chemical system, which would make the numerical model stiffer and less accurate. A suitable approach is to include in the chemical system only the most relevant chemical species and chemical reactions to model the behaviour of interest.

The simulation results showed that the model represented fairly well the overall reactive transport phenomena. However, excessively sharp concentration profiles of $\mathrm{Pb}$ and $\mathrm{Ca}$ were observed in those simulations, associated with the solids dissolution kinetics. In this work, the model has been expanded to include the kinetics of the dissolution of calcite. The dissolution of the $\mathrm{Pb}$-containing mineral is still assumed fast enough to be included in the LCE module. This is congruent with the results presented in [18], that demonstrated that calcite dissolution was kinetically limiting.

The chemical reactions taken into account were: (1) electrolysis reactions at the electrodes, (2) aqueous phase complexation, and (3) precipitation and dissolution reactions, listed in Table 2.

\begin{tabular}{|c|c|c|c|}
\hline Species & Stoichiometry & $\begin{array}{l}D_{i} \times 10^{9} \\
\left(\mathrm{~m}^{2} \mathrm{~s}^{-1}\right)\end{array}$ & $\log _{10}\left(K_{e q}\right)$ \\
\hline \multicolumn{4}{|c|}{ Electrolysis reactions } \\
\hline $\mathrm{H}_{2} \mathrm{O}$ & \multicolumn{2}{|l|}{$\rightarrow 2 \mathrm{H}^{+}+2 e^{-}+\frac{1}{2} \mathrm{O}_{2}(\mathrm{~g})$} & - \\
\hline \multicolumn{2}{|c|}{ Aqueous species and water } & & \\
\hline $\mathrm{H}^{+}$ & - & $9.311^{\mathrm{b}}$ & - \\
\hline $\mathrm{OH}^{-}$ & - & $5.273^{b}$ & - \\
\hline $\mathrm{Na}^{+}$ & - & $1.334^{\mathrm{b}}$ & - \\
\hline $\mathrm{Ca}^{2+}$ & - & $0.792^{b}$ & - \\
\hline $\mathrm{CO}_{3}^{2-}$ & - & $0.923^{b}$ & - \\
\hline $\mathrm{Ac}^{-}$ & - & $1.084^{\mathrm{b}}$ & - \\
\hline $\mathrm{Pb}^{2+}$ & - & $0.945^{b}$ & - \\
\hline $\mathrm{H}_{2} \mathrm{O}$ & $\leftrightarrows \mathrm{H}^{+}+\mathrm{OH}^{-}$ & $250^{\mathrm{b}}$ & $14^{\mathrm{a}}$ \\
\hline $\mathrm{HCO}_{3}^{-}$ & $\leftrightarrows \mathrm{H}^{+}+\mathrm{CO}_{3}^{2-}$ & $1.185^{\mathrm{b}}$ & $10.33^{\mathrm{a}}$ \\
\hline $\mathrm{CaHCO}_{3}^{+}$ & $\leftrightarrows \mathrm{H}^{+}+\mathrm{Ca}^{2+}+\mathrm{CO}_{3}^{2-}$ & $1.185^{\mathrm{c}}$ & $11.6^{\mathrm{a}}$ \\
\hline $\mathrm{PbHCO}_{3}^{+}$ & $\leftrightarrows \mathrm{H}^{+}+\mathrm{Pb}^{2+}+\mathrm{CO}_{3}^{2-}$ & $1.185^{\mathrm{c}}$ & $13.2^{\mathrm{a}}$ \\
\hline $\mathrm{H}_{2} \mathrm{CO}_{3}$ & $\leftrightarrows 2 \mathrm{H}^{+}+\mathrm{CO}_{3}^{2-}$ & $1.910^{\mathrm{b}}$ & $16.68^{a}$ \\
\hline HAc & $\leftrightarrows \mathrm{H}^{+}+\mathrm{Ac}^{-}$ & $1.210^{\mathrm{b}}$ & $4.76^{\mathrm{a}}$ \\
\hline $\mathrm{CaAc}^{+}$ & $\leftrightarrows \mathrm{Ca}^{2}+\mathrm{Ac}^{-}$ & $0.792^{\mathrm{c}}$ & $1.18^{\mathrm{a}}$ \\
\hline $\mathrm{PbAc}^{+}$ & $\leftrightarrows \mathrm{Pb}^{2}+\mathrm{Ac}^{-}$ & $0.945^{\mathrm{c}}$ & $2.68^{\mathrm{a}}$ \\
\hline \multicolumn{4}{|l|}{ Solid phases } \\
\hline \multirow{2}{*}{\multicolumn{2}{|c|}{$\begin{array}{l}\mathrm{CaCO}_{3}(\mathrm{~s}) \\
2 \mathrm{PbCO}_{3} \cdot \mathrm{Pb}(\mathrm{OH})_{2}(\mathrm{~s})\end{array}$}} & & $8.48^{\mathrm{a}}$ \\
\hline & & $+2 \mathrm{OH}^{-}$ & $14.49^{\mathrm{a}}$ \\
\hline
\end{tabular}

Table 2. Chemical Stoichiometry of the modeled chemical system 
As mentioned before, the kinetics of calcite dissolution is included in the model, while all other chemical reactions were still implemented under the LCE assumption. The rate of dissolution of calcite was assumed to follow the general rate law [16,24]:

$$
\frac{\partial m}{\partial t}=k A_{0}\left(\frac{m}{m_{0}}\right)^{\alpha}
$$

where $A_{0}\left(\mathrm{~m}^{2} / \mathrm{kg}\right)$ is the initial specific surface area, $m$ (mol) is the amount of solid, the exponent $\alpha(-)$ accounts for changes in the specific surface area of the particles during dissolution, and $k$ $\left(\mathrm{mol} \mathrm{m}^{-2} \mathrm{~s}^{-1}\right)$ is the specific rate constant, defined as:

$$
k=k_{f}\left[1-\left(\frac{I A P}{K_{s p}}\right)^{\beta}\right]
$$

where $k_{f}\left(\mathrm{~mol} \mathrm{~m}^{-2} \mathrm{~s}^{-1}\right)$ is a forward constant [16], IAP $(-)$ is the ion activity product, $K_{\mathrm{sp}}(-)$ is the solubility product constant and $\beta(-)$ is a coefficient related to the stoichiometry of the reaction ( $\beta=2 / 3$ for calcite, assuming spherical particles). It should be noted that (IAP $\left./ K_{s p}\right)>1$ for supersaturation, $\left(\mathrm{IAP} / K_{s p}\right)<1$ for undersaturation and $\left(\mathrm{IAP} / K_{s p}\right)=1$ in the precipitation/dissolution equilibrium. Therefore, the simplified kinetic law used here is function of the distance to the equilibrium and it accounts for both precipitation and dissolution.

\subsection{Transport phenomena}

The transport of aqueous species and water through porous media under an applied electric field is described as a combination of diffusion, electromigration and electroosmosis. Herein, pore fluid advective transport is neglected, due to the low hydraulic permeability of the soils usually treated via EKR. Similarly, electrophoresis has limited relevance in EKR since colloid migration is hindered by the immobile phase of the porous medium [25]. Accordingly, the mass transport equation of the $i$-th chemical species, based on the Nernst-Planck (NP) equation [26], is described as

$$
p \frac{\partial c_{i}}{\partial t}=\nabla\left[\frac{p}{\tau}\left(D_{i} \nabla c_{i}-\left(U_{i}+k_{e o}\right) c_{i} \nabla \phi\right)\right]+p G_{i}
$$

where $p(-)$ is the porosity, $\tau(-)$ is the tortuosity, $c_{i}\left(\mathrm{~mol} \mathrm{~m}^{-3}\right)$ is the concentration, $D_{i}\left(\mathrm{~m}^{2} \mathrm{~s}^{-1}\right)$ is the diffusion coefficient, $U_{i}\left(\mathrm{~m}^{2} \mathrm{~s}^{-1} \mathrm{~V}^{-1}\right)$ is the ionic mobility, $\phi(\mathrm{V})$ is the electric potential, $k_{e o}$ $\left(\mathrm{m}^{2} \mathrm{~s}^{-1} \mathrm{~V}^{-1}\right)$ is the electroosmotic permeability and $G_{i}\left(\mathrm{~mol} \mathrm{~m}^{-3} \mathrm{~s}^{-1}\right)$ represents a volumetric net source due to chemical reactions.

The Nernst-Townsend-Einstein relation [27] was applied to relate diffusivity to the ionic mobility:

$$
U_{i}=\frac{D_{i} z_{i} F}{R T}
$$


where $z_{i}(-)$ is the ionic charge, $F\left(\mathrm{C} \mathrm{mol}^{-1}\right)$ is the Faraday's constant, $R\left(\mathrm{~J} \mathrm{~K}^{-1} \mathrm{~mol}^{-1}\right)$ is the ideal gas constant and $T(\mathrm{~K})$ is the temperature.

The electric potential $\phi$ is computed by solving the current conservation equation:

$$
\nabla \cdot \mathbf{J}=0
$$

where $\mathbf{J}\left(\mathrm{A} \mathrm{m}^{-2}\right)$ denotes the current density, described by the Ohm's law, $\mathbf{J}=-\sigma \nabla \phi$, and $\sigma\left(\mathrm{S} \mathrm{m}^{-}\right.$ $\left.{ }^{1}\right)$ denotes the electrical conductivity, which is related to pore fluid conductivity $\sigma_{w}\left(\mathrm{~S} \mathrm{~m}^{-1}\right)$ by $\sigma=p \tau \sigma_{w}$. This implies that the solid phase surface conductivity is negligible and that the local electroneutrality condition $\left(\sum c_{i} z_{i}=0\right)$ is fulfilled. The externally-applied current density is a boundary condition for Eq. 6 , where the anode represents a current source and the cathode a current sink. The pore fluid conductivity, $\sigma_{w}$, is calculated by taking into account the conductivity of all the species in the pore solution, while correcting the molal concentration with an electrochemical activity coefficient that is derived from the combination of the Kohlrausch's law and the DebyeHückel equation [28].

\subsection{Numerical model}

Transport processes and chemical reactions were implemented using a two-steps sequential split-operator scheme $[7,8]$. In the first step, the transport equation system (accounting for diffusion, electromigration and electroosmosis and the water electrolysis reactions at the electrode, under electroneutrality conditions) is numerically integrated by means of a finite element method. In the second step, the chemical equilibrium reactions are calculated. A diagram describing the numerical implementation is shown in Fig. 2. 


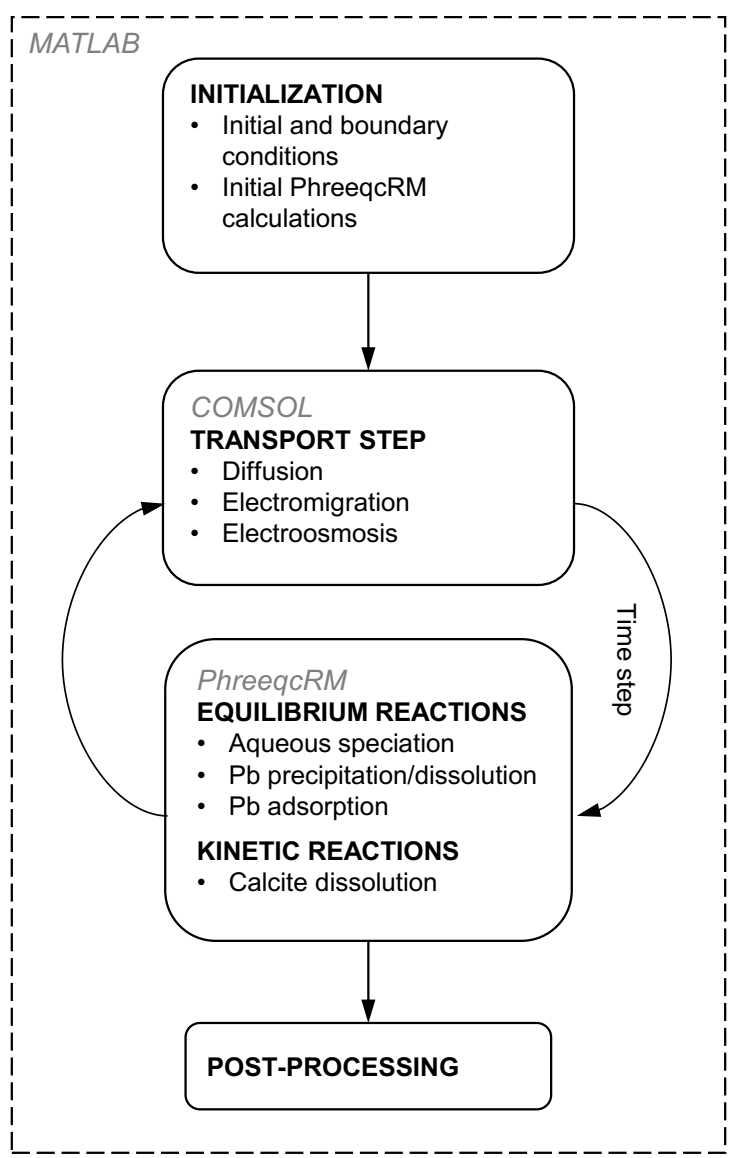

Figure 2. Structure of the numerical implementation

While the simulation results presented in previous works [12] were carried out using a tailor made code fully written in Matlab®, the numerical procedure presented in this work was achieved by coupling two specialized software packages; namely COMSOL Multiphysics and PHREEQC. COMSOL was used for the solution of the finite element integration of the transient NernstPlanck-Electroneutrality system of algebraic and partial differential equations, while the algebraic system of chemical equilibrium equations, accounting for the formation of aqueous complexes, precipitation and dissolution reactions, were computed using the PHREEQC [28]. It should be noted that the transient dissolution/precipitation reaction of calcite was also included in the PHREEQC script as a kinetic reaction module. The coupling between COMSOL and PHREEQC was attained using an envelope Matlab ${ }^{\circledR}$ script, as shown in Fig. 2, which is also used to initialize the system and postprocess the results.

\section{Results and discussion}

\subsection{Simulation of a water-calcite system}

In order to evaluate the influence of the reaction kinetics of the calcite dissolution, a simple water-calcite system was modeled. This system consisted of $1 \mathrm{~kg}$ of water in equilibrium with atmospheric $\mathrm{CO}_{2}$ put in contact with $120 \mathrm{~g}$ of pure calcite, assuming fine particles with a specific 
surface of $10 \mathrm{~m}^{2} \mathrm{~g}^{-1}$. This water/calcite ratio was congruent with that in the real soil used in the experiments in [19]. Figure 3 shows transient profiles for $\mathrm{pH}$ and total dissolved calcium, including not only $\mathrm{Ca}^{2+}$, but also the complexes $\mathrm{CaOH}^{+}, \mathrm{CaAc}^{+}$and $\mathrm{CaHCO}_{3}$. The simulations correspond to four different cases, in which the mass of water was initially at $\mathrm{pH}$ values of 2, 3, 4 and 5. These values are also representative of the acid-enhanced EKR experimental results.

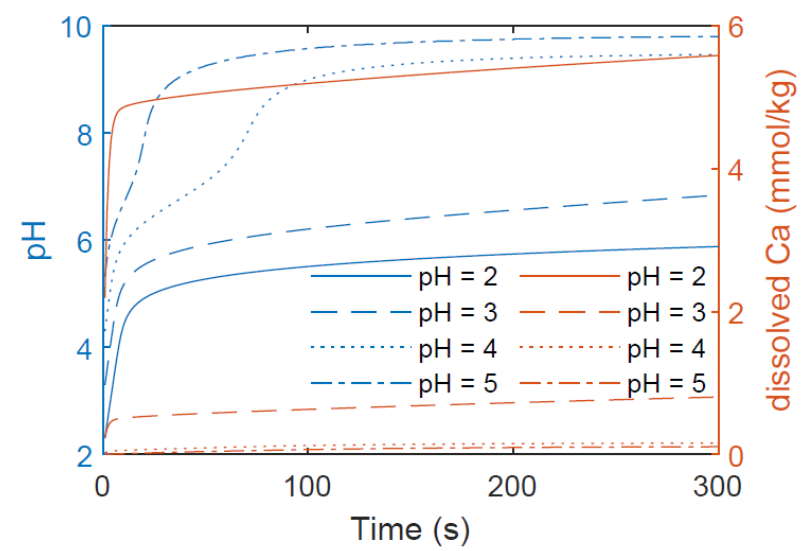

Figure 3. Dissolved $\mathrm{Ca}$ and $\mathrm{pH}$ transient profiles for the dissolution of calcite in pure water at different initial $\mathrm{pH}$ values, obtained via PHREEQC simulations.

Figure 3 shows that the dissolution of calcite particles in the treated calcareous soil is not reaching chemical equilibrium in a period of time short enough to be considered faster than the transport processes. As expected, low $\mathrm{pH}$ environments promote a faster dissolution of the mineral. However, even at $p H=2$, the system requires approximately $100 \mathrm{~s}$ to reach moderately stable profiles, which is higher than the representative time scale of the electromigration transport mechanism.

It should be noted that, despite the calcite dissolution reaction into $\mathrm{Ca}^{2+}$ and $\mathrm{CO}_{3}{ }^{2-}$ is limited by its kinetics, the rest of the species in the system are considered to reach chemical equilibrium instantaneously. The dissolution of the calcite becomes, in this model, a limiting stage of the chemical process, and competes with the transport transient equations on the overall remediation dynamics.

\subsection{Simulation of experimental data}

In this section, the simulation results from the model proposed here, accounting for the kinetic of the dissolution of calcite and LCE for the rest of the species, are presented and compared to the experimental data Villen-Guzman et al., 2015 [19] and the simulation results assuming all chemical reactions under the LCE assumption. The results correspond to $15 \mathrm{~d}$ of acid-enhanced treatment, using acetic acid for buffering the cathode compartment to $\mathrm{pH}<5$ and using constant current density of $2 \mathrm{~mA} \mathrm{~cm}^{-2}$. The parameters used in the simulations are listed in Table 3 .

Table 3. Model parameters.

Parameter Value Unit Description




\begin{tabular}{cccl}
\hline$\tau$ & 2.25 & - & Tortuosity factor \\
$p$ & 0.49 & - & Porosity \\
$\alpha$ & $2 / 3$ & - & Exponent Equation 1 \\
$A_{0}$ & 10 & $\mathrm{~m}^{2} / \mathrm{g}$ & Specific area of calcite particles \\
$\beta$ & $2 / 3$ & - & Parameter Equation 2 \\
\hline
\end{tabular}

In Fig. 4, it can be seen that the $\mathrm{pH}$ value at the anode end is near $\mathrm{pH}=2$, and it gradually increases to $\mathrm{pH}=5.6$, which is the equilibrium $\mathrm{pH}$ value of calcite in acidic solution. The experimental data indicate that in the regions closer to the anode, the calcite was totally dissolved, while approximately half of the soil column still has most of the initial calcite. In the case of using the LCE assumption, a sharp step from $\mathrm{pH}=2$ to almost $\mathrm{pH} 6.5$ is detected at approximately $8 \mathrm{~cm}$ from the anode.

The simulations carried out considering the kinetics of the dissolution of the calcite reproduce the $\mathrm{pH}$ profile with high accuracy, gradually adapting from the low $\mathrm{pH}$ region at the anode to the stable $\mathrm{pH}$ of 5.6 at the middle region of the soil column.

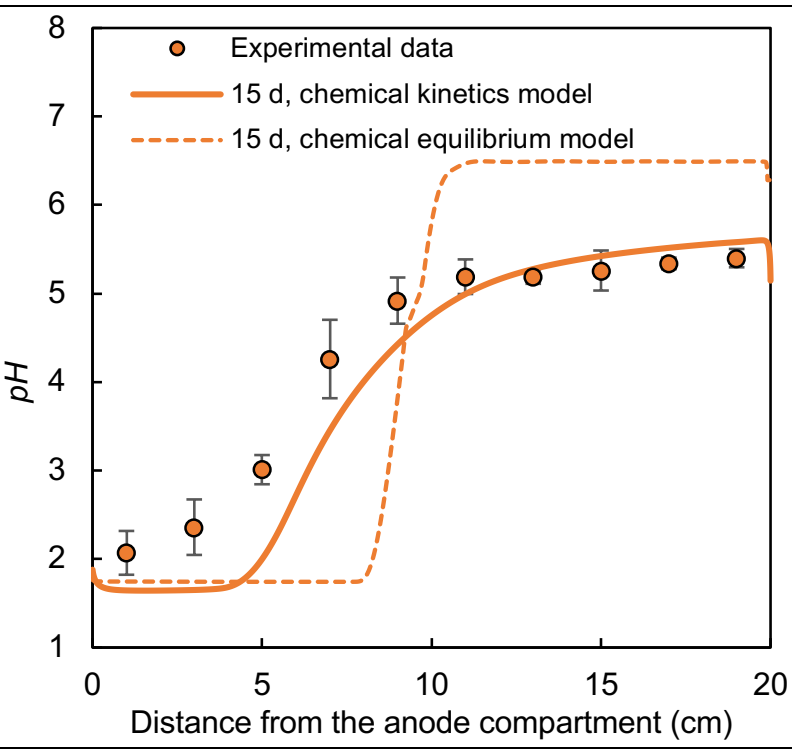

Figure 4. $\mathrm{pH}$ profile in the column soil.

Figure 5 shows the total amount of $\mathrm{Ca}$, including the existing in the mineral and the $\mathrm{Ca}$ dissolved in the pore solution including $\mathrm{Ca}^{2+}$ and the aqueous complexes $\mathrm{CaHCO}_{3}{ }^{+}, \mathrm{CaAc}^{+}$and $\mathrm{CaOH}^{+}$. In a similar way than in the $\mathrm{pH}$ profile, the total $\mathrm{Ca}$ profile obtained in the simulations considering the dissolution kinetics of the calcite matches with high accuracy the experimental results. The LCE simulations results showed sharp profiles, predicting a region of totally dissolved calcite that progress from anode to cathode with the acid front. The simulations obtained using the dissolution kinetics results in a more realistic profile, with high prediction capability. 


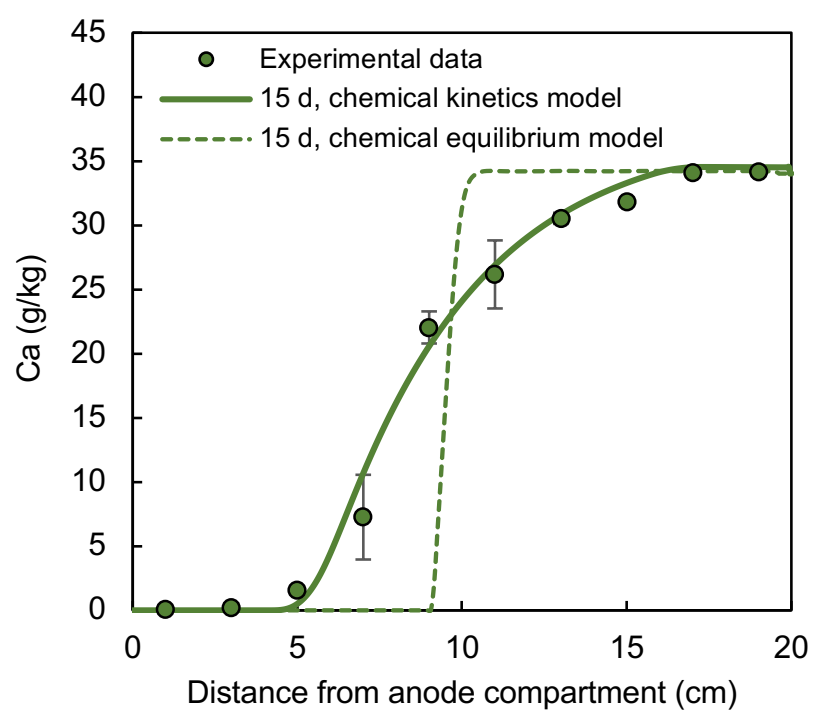

Figure 5. Ca profile in the column soil

In the case of the $\mathrm{Pb}$, which is the main target contaminant in the discussed EKR treatment, the concentration profile of the total dissolved metal is shown in Fig. 6. Comparing the experimental data with the simulation results obtained using the two compared models show important differences. Simulation results obtained under chemical equilibrium assumption shown slower removal of $\mathrm{Pb}$ compared to the experimental data. Under the application of the chemical kinetic model, simulations results reproduce the experimental data with higher accuracy than for the case of applying LCE model, especially in the soil close to the anode compartment. The observed divergences between experimental data and results of chemical equilibrium model could be related to the precipitation processes taken place in soil close to cathode.

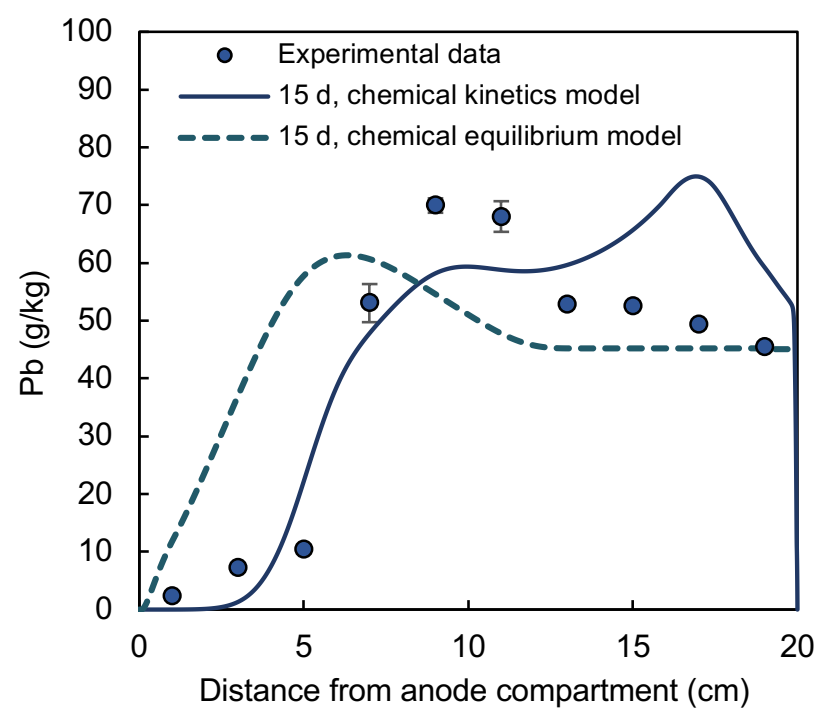

Figure 6. $\mathrm{Pb}$ profile in the column soil. 
The model presented here has the potential to be used not only in simulating electrokinetic remediation processes, but also in modelling reactive-transport in porous media in general way, with and without the existence of an external electric field, as in geochemical process, porous catalysts or membranes processes. Adapting the model to different systems is moderately easy, provided the chemical system and the limiting processes, either transport mechanisms or chemical reactions, are known. Future improvements of the model should address the prediction of the electrode process. A better understanding of the electrode overpotentials could allow to predict the energy consumption of EKR processes, and to allow the economical optimization of the remediation treatments.

\section{Conclusions}

The mathematical model presented here considers the reactive-transport in porous media considering the local chemical equilibrium assumption for most of the chemical reactions, except for those considered with representative in the same order of than the transport processes. In the example presented here, the kinetic rate of the dissolution of calcite is included in a local chemical equilibrium for acid-enhanced electrokinetic remediation of $\mathrm{Pb}$ contaminated soil.

The prediction capability of the model has been clearly improved, compared with the simulations results performed using local chemical equilibrium for all reversible reactions. These results prove that the kinetic reactions can dominate the overall rate of the remediation processes for some specific cases. Although the mathematical model has been implemented for soil, it is easily adaptable to other porous matrices such as sludge, construction materials or sediments. That way, the described mathematical model is a potential tool for specific cases in which the kinetic chemical processes are relevant without adding a high level of complexity to local chemical equilibrium models previously studied.

\section{Acknowledgements}

This work has received funding from the European Union's Horizon 2020 research and innovation programme under the Marie Skłodowska-Curie grant agreement No. 778045. Part of this work was supported financially by the European Commission within the project LIFE12 ENV/IT/442 SEKRET "Sediment electrokinetic remediation technology for heavy metal pollution removal". Paz-Garcia acknowledges the financial support from the "Proyecto Puente - Plan Propio de Investigación y Transferencia de la Universidad de Málaga", code: PPIT.UMA.B5.2018/17. Villen-Guzman acknowledges the financial support from the University of Malaga through a postdoctoral contract.

\section{References}

[1] J.M. Paz-García, B. Johannesson, L.M. Ottosen, A.B. Ribeiro, J.M. Rodríguez-Maroto, Computing multi-species chemical equilibrium with an algorithm based on the reaction 
extents, Comput. Chem. Eng. 58 (2013) 135-143.

doi:10.1016/j.compchemeng.2013.06.013.

[2] D. Langmuir, Aqueous Environmental Geochemistry, Prentice Hall, 1997.

[3] A.Z. Al-Hamdan, K.R. Reddy, Electrokinetic remediation modeling incorporating geochemical effects, J. Geotech. Geoenviron. Eng. 134 (2008) 91-105. doi:10.1061/(ASCE)1090-0241(2008)134:1(91).

[4] A.N. Alshawabkeh, Y.B. Acar, Electrokinetic remediation. II: Theoretical model, J. Geotech. Geoenviron. Eng. 122 (1996) 186-196.

[5] S. Amrate, D.E. Akretche, Modeling EDTA enhanced electrokinetic remediation of lead contaminated soils, Chemosphere. 60 (2005) 1376-1383. doi:10.1016/j.chemosphere.2005.02.021.

[6] S.-O. Kim, J.-J. Kim, S.-T. Yun, K.-W. Kim, Numerical and experimental studies on cadmium (II) transport in kaolinite clay under electrical fields, Water, Air, and Soil Pollution. 150 (2003) 135-162. doi:10.1023/A:1026181800685.

[7] M. Masi, A. Ceccarini, R. Iannelli, Multispecies reactive transport modelling of electrokinetic remediation of harbour sediments, J. Hazard. Mater. 326 (2017) 187-196. doi:10.1016/j.jhazmat.2016.12.032.

[8] G. Skibsted, L.M. Ottosen, P.E. Jensen, J.M. Paz-Garcia, Electrochemical desalination of bricks - Experimental and modeling, Electrochim. Acta. 181 (2015) 24-30. doi:10.1016/j.electacta.2015.03.041.

[9] A.A. Javadi, M.M. AL-Najjar, Finite element modeling of contaminant transport in soils including the effect of chemical reactions, J. Hazard. Mater. 143 (2007) 690-701. doi:10.1016/j.jhazmat.2007.01.016.

[10] J.M. Rodríguez-Maroto, C. Vereda-Alonso, Electrokinetic Modeling of Heavy Metals, in: K.R. Reddy, C. Camesselle (Eds.), Electrochemical Remediation Technologies for Polluted Soils, Sediments and Groundwater, Wiley Online Library, 2009: pp. 537-562. doi:10.1002/9780470523650.ch25.

[11] J.M. Paz-Garcia, K. Baek, I.D. Alshawabkeh, A.N. Alshawabkeh, A generalized model for transport of contaminants in soil by electric fields, J. Environ. Sci. Health Part A Toxic Hazard. Subst. Environ. Eng. 47 (2012) 308-318. doi:10.1080/10934529.2012.640911.

[12] J.M. Paz-García, M. Villén-Guzmán, A. García-Rubio, S. Hall, M. Ristinmaa, C. GómezLahoz, A coupled reactive-transport model for electrokinetic remediation, in: Electrokinetics Across Disciplines and Continents: New Strategies for Sustainable Development, Springer International Publishing, 2015: pp. 251-278. doi:10.1007/978-3319-20179-5 13.

[13] M. Masi, A. Ceccarini, R. Iannelli, Model-based optimization of field-scale electrokinetic treatment of dredged sediments, Chem. Eng. J. 328 (2017) 87-97. doi:10.1016/j.cej.2017.07.004.

[14] M. Villen-Guzman, P. Guedes, N. Couto, L.M. Ottosen, A.B. Ribeiro, J.M. RodriguezMaroto, Electrodialytic phosphorus recovery from sewage sludge ash under kinetic control, Electrochim. Acta. (2018). doi:10.1016/j.electacta.2018.08.032.

[15] R.A. Jacobs, R.F. Probstein, Two-Dimensional Modeling of Electroremediation, AIChE Journal. 42 (1996) 1685-1696. doi:10.1002/aic.690420620.

[16] L.N. Plummer, T.M.L. Wigley, D.L. Parkhurst, The kinetics of calcite dissolution in CO2water systems at 5 degrees to 60 degrees $\mathrm{C}$ and 0.0 to $1.0 \mathrm{~atm} \mathrm{CO} 2$, American Journal of Science. 278 (1978) 179-216. doi:10.2475/ajs.278.2.179. 
[17] Y.B. Acar, A.N. Alshawabkeh, R.J. Gale, Fundamentals of extracting species from soils by electrokinetics, Waste Manag. 13 (1993) 141-151.

[18] M. Villen-Guzman, J.M. Paz-Garcia, G. Amaya-Santos, J.M. Rodriguez-Maroto, C. Vereda-Alonso, C. Gomez-Lahoz, Effects of the buffering capacity of the soil on the mobilization of heavy metals. Equilibrium and kinetics, Chemosphere. 131 (2015) 78-84. doi:10.1016/j.chemosphere.2015.02.034.

[19] M. Villen-Guzman, J.M. Paz-Garcia, J.M. Rodriguez-Maroto, F. Garcia-Herruzo, G. Amaya-Santos, C. Gomez-Lahoz, C. Vereda-Alonso, Scaling-up the acid-enhanced electrokinetic remediation of a real contaminated soil, Electrochim. Acta. 181 (2015) 139145. doi:10.1016/j.electacta.2015.02.067.

[20] M. Villen-Guzman, J.M. Paz-Garcia, J.M. Rodriguez-Maroto, C. Gomez-Lahoz, F. GarciaHerruzo, Acid Enhanced Electrokinetic Remediation of a Contaminated Soil using Constant Current Density: Strong vs. Weak Acid, Sep. Sci. Technol. 49 (2014) 1461-1468. doi:10.1080/01496395.2014.898306.

[21] M. Villen-Guzman, A. Garcia-Rubio, J.M. Paz-Garcia, C. Vereda-Alonso, C. GomezLahoz, J.M. Rodriguez-Maroto, Aging effects on the mobility of $\mathrm{Pb}$ in soil: Influence on the energy requirements in electroremediation, Chemosphere. 213 (2018) 351-357. doi:10.1016/j.chemosphere.2018.09.039.

[22] D.L. Parkhurst, C. Appelo, User's guide to PHREEQC (Version 2): A computer program for speciation, batch-reaction, one-dimensional transport, and inverse geochemical calculations, (1999) 312.

[23] D.R. Lide, CRC handbook of chemistry and physics: a ready-reference book of chemical and physical data, CRC press, 1995.

[24] C.A.J. Appelo, D. Postma, Geochemistry, groundwater and pollution, CRC press, 2005.

[25] J.-W. Yu, I. Neretnieks, Modelling of transport and reaction processes in a porous medium in an electrical field, Chemical Engineering Science. 51 (1996) 4355-4368. doi:10.1016/0009-2509(96)00283-7.

[26] J.M. Paz-García, B. Johannesson, L.M. Ottosen, A.B. Ribeiro, J.M. Rodríguez-Maroto, Modeling of electrokinetic processes by finite element integration of the Nernst-PlanckPoisson system of equations, Sep. Purif. Technol. 79 (2011) 183-192. doi:10.1016/j.seppur.2011.02.023.

[27] A.N. Alshawabkeh, Y.B. Acar, Removal of Contaminants from Soils by Electrokinetics: A Theoretical Treatise, J. Environ. Sci. Health Part A Environ. Sci. Eng. Toxic Hazard. Subst. Control. 27 (1992) 1835-1861. doi:10.1080/10934529209375828. 